\title{
Communication theories and design practices of strategic communications in social field
}

\author{
Nina Starykh \\ Lomonosov Moscow State University, Russia
}

DOI: 10.30547/worldofmedia.2.2018.2

\begin{abstract}
The article analyzes modern communicative practice in the nonprofit sector in the context of the theory of strategic communications. The novelty of the ideas lies in the fact that, firstly, the strategic planning of social communication is poorly comprehended in comparison with commercial one, secondly, the certain methods of designing communication strategies are still the subject of debate. The author identifies three research traditions, on the basis of which the methods of developing communication strategies have been formed: positivistic psychological theories of behaviorism and cognitive science, Gestalt psychology and semiology. The article is concerned with the possibilities and limitations of three groups of methods in practice of social communication.
\end{abstract}

\section{Keywords}

Strategic communications in social field, sense structure of communication, communicative strategies, prosocial behavior, social advertising

\section{Introduction}

Whenever we wish to be understood, we organize the process of communication with other people in a special way by gauging their knowledge about the discussed topic, comparing our systems of values and finding out if the interlocutor can assess the situation from a different standpoint. Otherwise, a misunderstanding may occur which may result in a conflict. In other words, communication is an act of forming a unified semantic space between the engaged participants. While in interpersonal communication understanding may be achieved spontaneously due to empathy, in mass communication reaching it requires some reflexive

Corresponding author:

Nina Starykh, Faculty of Journalism, Lomonosov Moscow State University,

9 Mokhovaya street, Moscow, Russia.

Email: staryh@mail.ru 
effort. The reason for it is as following: both the addresser and the addressee, located at the opposite ends of a communicative act, are immersed in different social practices. Therefore, each side measures the object of discussion with its own set of parameters.

The main goal of any social project is to create a healthy society and promote healthy psychosocial attitudes and behavior among its members. The problem is that an individual and society are connected but not equal systems. A person being a part of this system is dependent on it; however, he or she is not often capable of thinking about the system as a whole. As a result, a variety of interpretations appears which sometimes exclude each other about what is considered as a social welfare. Developers of a charity project, who are oriented towards their personal views, propose their own versions. People who receive it tend to interpret it according to their own logic. The risks of mutual misunderstanding, mistrust, irony and insults are higher in social communication than in other spheres of life. For instance, a social campaign 'Buckets for cure' (The dangers of cause marketing, n.d.) arranged by KFC in partnership with a breast cancer fund Susan G. Komen. The fund offered its clients to buy pink buckets with fried meat under pretense of beating breast cancer.

One of the campaign's goals was its coverage in press, which was achieved, however, in a negative way as the brand KFC was condemned with hypocrisy. One of the bloggers called it 'another sad example of commercialism draped in pink ribbon' (Greed, cancer and pink KFC buckets, n.d.). So much for good intentions.

Controversy about a social campaign issued by a charity organization 'Barnardo's' is another example of misunderstanding we should point out as it was received quite poorly as well. The reason for its negative perception is the image chosen for the problem which is wide spoken and of a current interest children being born in poor families with extremely low income or even with absence of one. According to the official statistics, those kids are more likely to become alcoholics or drug addicts. In order to tackle this issue, the advertisement makers ended up using shock tactics by publishing an image of a baby with a huge cockroach trying to get out of the baby's mouth. Other images from the series featured babies consuming methylated spirit instead of baby formula or holding a syringe (presumably filled with narcotics). This strategy clearly backfired as British Advertising Standards Authority received 445 complaints from the audience with demands to remove the ad from public view (Social advertising shocks Britons, 2017). 


\section{Strategic communications in the social sphere: Statement of the question}

The examples of dysfunctional effects of advertising campaigns mentioned above only prove that social communication in the same way as a commercial one needs a strategic planning. Strategic communications is relatively a new trend in the theory of communication, being formed in 1980s as a response to the challenges of the creative revolution in the US and Europe, and the discussion about competence-based approach in education of the 21st century (Ross \& Richards, 2008).

If to omit the dramatic details of the plot about the confrontation between practitioners and representatives of the academic environment, the problem was to find such a solution in the formation of advertisers, which would satisfy the two ones, at first glance, mutually exclusive conditions. At first, consistency and solidity of academic education should be kept. The qualification level of a specialist with a university education implies that he/she is able to respond not only to the question 'How to do?' but 'Why is it possible to do?', 'What is the essence of what I'm doing?', that is to have a special professional motivation and to see the entire production process as a whole, not just separate operating units. Secondly, the fundamental knowledge must be combined with the applied skills.

The contradiction was solved thanks to a rethinking of the concept of 'application'. These are not 'manual' skills but pragmatic special installation on projective thinking. Design thinking in conjunction with systemic academic knowledge develops creative abilities of a specialist, it allows to solve complex problems not fitting patterns.

The founders of the theory of strategic communications are considered to be professor D. Shultz and his colleagues at Northwestern University, USA, having offered the course 'Integrated marketing communications' (Schultz, Tannenbaum, \& Lauterborn, 1994). Since 1950, management by goals, making up the point of strategic management, has been successfully applied in business practice at the highest levels of planning. However, only in 1980 communication activity was comprehended in the context of business processes - consequently interconnected technological operations aimed at achieving the set goals. This logic suggests standardization of communication, which includes the development of specific and measurable indicators of the quality of communication technology at the entrance, as well as evaluation of costeffectiveness of the output. The problem consisted in the specification of indicators, measuring marketing communication.

As it is known, the marketing complex includes four instruments designated with a formula ' $4 \mathrm{P}$ ' - product development, pricing and delivery system to the 
point of sales, and promotions. Together, they are working to manage customer behavior - whether it's buying and other kinds of business transactions that affect the income of the organization.

The competence of marketing communication is formation of behaviors' installations that can be measured with the help of intermediate variables awareness and attitude. In other words, the communication has been conceptualized by Schultz and his followers on the basis of psychological theory of behavior, interpreting the behavior as a response to external stimuli ( $->\mathrm{R}$ ).

Statistical comparison by the transitions to purchases from the side of aware and loyal customers has allowed the researchers to identify sustainable coefficients regardless of the sphere of commodity production or services. Empirically identified coefficients of conversion allow to plan and control the financial contribution of communication in business strategy, give it the status of strategic communication.

Undoubtedly, strategic planning of communication activity can and should be applied not only in situations of economic relations. Efficiency is important in any field, whether it be political, social or spiritual sphere. Because the sustainable development of any social system is connected with the satisfaction of both material and spiritual needs of included in it individuals. Generally valid tasks are the attractors, uniting the efforts of individuals, organizations and government agencies. Macrostructures, combining human, power, organizational and material resources in the name of socially significant goals are called social institutions. If to talk about the institute of social protection of the population, precisely in the context of its activities it should be considered the activity and goals of the communication for non-profit organizations included in it by functionality. The mission of the institute of social protection implementation of the idea of social justice, the promotion of values and norms of social interaction, strengthening social health and social capital. Indeed, shared by the majority ideas about good and evil, norms of behavior is the basis for the identity of individuals as citizens, the basis of their loyalty to a particular national community. Without this loyalty people turn into population, though living in the same territory, but unable to protect it.

The structure of the institution of social security is isomorphic to the 'technical process' by the production of social services, which is always built based on representations about the quality of these services, and in our case the concrete historical notions of social justice and the needs of the future. It is possible to talk about a variety of social and cultural models of social protection institutions, where the main customers and sponsors are tribal leaders and elders, government, business, people... Accordingly, financial support of 
initiative projects in different times and in different cultures depends on various institutional actors, their visions of social health, behavior of the problematic social groups and social rehabilitation tools.

However, we emphasize the main conclusion of our previous argument: at the level of goal setting of a social campaign, it is always possible to identify and analyze the problem of the functioning of the social whole, it should be noted by the target groups involved in it, to formulate problems of current behavior, to implement communication, to encourage certain forms of activity, to monitor their implementation through intermediate variables of awareness and attitudes.

The point in the development of strategic communications theory is related to the search for methods of designing a communication strategy.

\section{Theoretical and methodological approaches in the design of communication strategies American School: Positivism in the treatment of communication strategy}

American School is developing this perspective on the same positivist methodological basis of behavior. Statistical analysis of the factors influencing the awareness and relation of the target audience in relation to the subject of the advertising message, identifies the meta-model of decision-making. Communicative strategy is here understood as encouraging decision-making processes. This approach is currently the most influential in the theory and practice of strategic communications. However, it is not perfect.

Since the situation of the decision changes the set of communicative impact models is multiplied, and this search is still not seen in the end. In professional journals skepticism about AIDA, AIMDA, DAGMAR, FCB and other abbreviations often sounds, giving the name of the universal logic of the decision and claims to be open to communication code. However, renounce of these models is impossible, because they allow communication with intermediate measurements of the position of an object, and thus give it the status of the strategic. There is only one way out here: to be armed with a preliminary hypothesis, to recheck the accuracy of its additional research specific target audiences. It is important for the specialist to determine the key factors in the decision, or positioning, which gives a positive trend throughout the decision-making process.

For example, the simplest everyday situations related to consumer behavior, a positive attitude to the product is directly connected with the idea of its own benefit, that is, with the conviction that its functional characteristics are best placed to meet the needs. 
However, the behavior in more complex situations with a focus on the social environment, is motivated by altruism and mutual assistance, and is characterized by a more complex reflexive structure. As a general rule, a decision to help one's neighbor is made under the influence of emotional factors: compassion for those in need, a sense of duty to help, etc. Prosocial behavior, however, does not exclude rationality in the behavior of the helper. Assistance can also be harmful. If you give money to a neighbor who has problems with alcohol addiction objectively, this is aid. But what will be the result? A drunk neighbor who bothers the neighborhood. One can hardly say that this is worth doing. If sponsors come to an orphanage and give presents to the homeless children, the latter form the philosophy of the poor and learn to live a parasitic lifestyle.

Issues arising from the ambiguity of assistance motivated the study of cognitive psychologists J. Howard and Sh. Schwartz. In 1981, they proposed a model of helping action, which includes five types of cognitive processes that characterize the logic of assisting decision-making: attention - motivation evaluation - protection - behavior (Ilyin, 2013).

This model starts from the moment of awareness of the situation, when someone needs help. Phase of attention includes recognition of someone else's misfortune, the selection of effective prosocial activities and recognition of him-/ herself as ready to help. The essence of the next phase - the phase of motivation is construction of personal standards and updating of personal liability according to social values, followed by generating a sense of moral duty. The third stage assessment of expected impact of prosocial actions - includes an assessment of potential costs and acquisitions. The cost in this case is made up of social costs (for example, the risk of social disapproval), physical costs (pain), and moral costs (which would be the result of a breach of individual norms). At the stage of protection, a person can develop a reason to refuse the responsibility for someone else's misfortune. Preference may be given to personal interests, and responsibility for others may be rejected as an unfair requirement. This is due to the fact that people follow normative expectations regarding the level of their deserved rewards and costs. At the same time, the responsibility for the decision to act or not to act may be perceived as conflicting obligations, or a person may decide that it lacks the necessary capacity for intervention and resources. The last stage - acting or refraining from action, depends on the result acquired by the process of decision-making.

\section{Postmodern interpretation of a communication strategy}

Despite the diversity of theoretical directions of postmodern science, they are ideologically united, they are rebuilt from the positivism with its rationalistic 
attitude toward knowledge. Knowledge is not only a product of thinking, but unconscious.

Thinking operates with static cognitive constructs (frames), through which an individual assigns values to the phenomena from the surrounding world. This knowledge, from the point of the postmodernists is burdened with two significant disadvantages: firstly, it is inevitably fragmentary, secondly, it assesses the present in terms of experience, which took place in the past, that is, disturbs the perception of reality. The knowledge that is stored in the unconscious, ensures the integrity of understanding due to the fact that the ability to grasp things and events in their essence - meanings. The meaning is dynamic, always in opposition to established values. Mobility sense, which distinguishes it from the value, because it balances between the conscious and the unconscious. It involved the creation of the psychological mechanism of the imagination, which, in contrast to the thinking, is able to seek answers to urgent questions directly in the 'files' stored in the unconscious.

The memory of the unconscious mind is much more volumetric than the memory of the conscious mind, because it stores all the information, fixed physical organs of perception, including the one that consciousness simply does not notice. This idea, advanced by Sigmund Freud, has become a reference for the postmodern philosophy, justified them by using a witty analogy - an experimental design 'wonderful waxy block' (Derrida, 2000). Since the unconscious, as opposed to the consciousness retains all of the information tracks recorded by physiological sense organs, then any of their stable repetition forms a bizarre network of concrete sensory images associative logic, i.e. bonds, is not obvious to the 'day of thinking' and the usual order things that determines our everyday lives. The order of everyday life is not the only possible, its limitations are understood by the collision with intrapersonal and social conflicts that cannot be solved by existing mental patterns. The solution is stored in the unconscious, but it is on the unconscious and that access is closed to consciousness. The channel, which connects the conscious and the unconscious - imagination that 'wakes up' the internal setting to solve the problem. The mechanism of the imaging mechanism is similar to the dream, as described by Freud, and performs the function of a translator from the language of the unconscious mind in the language (Freud, 2004). Extruded into the unconscious, the rest of the daily experience breaks in the dreamer's preconscious in the form of recognizable images but included in the amazing scenario. It requires reflexive effort to interpret their symbolic meaning. When this meaning is derived, personal and cultural memory is enriched with a new meaning, embodying code of lived experience. 
With the philosophical notion 'meaning' the term 'idea' is related, which is used in communication management theory. The creative idea of trying to grab the characteristic manifestations of the fact is that no extraneous material has a pronounced shape. It is integral that captures steady repetition in different representations of ranks (cognitive constructs), synthesizes a similar personal experience and the image of the world.

For postmodern culture expanding the boundaries of their own experience through other practices regarded as a key value of - way of updating the 'I' and personal growth. In the postmodern philosophy another important concept was developed - 'Other' - the logical-semantic space generated in the context of different life experiences, different social practices. This idea was picked up by a generation of rebellious era of creative revolution in 1970-1980. This is the way meant by Timothy Leary, when applied to the 30-thousandth of a crowd of hippies gathered January 14, 1967 in Golden Gate Park, with the famous phrase: 'including, attitude, attacks! (Turn on, tune in and drop out)!'

\section{The theory of brand communication: Gestalt psychological direction in the development of communication strategies}

The new socio-cultural context led to reinterpretation of the strategic communication model. If the archetypes of the collective unconscious, or gestalts, precede any communicative actions, they allow anyone to intuitively correctly distinguish lies from truth, sincerity from deceit, folly from wisdom, etc. Therefore, Gestalt-psychology followers radically rethink about the model of successful communication. A key element in the system is the personality of the speaker, the credibility of the one who speaks.

In scientific use of the communication management, the concept of branding, understood as a process of development of a trusting relationship between the trademark and the consumer, is introduced. As a full perception of the personality can be formed on the characteristic features of behavior in different situations, the brand is designed as a simulative model of personality, manifesting itself not only in the narrow niche of consumer behavior (traditionally occupied by traders), but positioning itself regarding the role expectations of a higher order: social and group membership, professional status and spiritual values. The main thing is that all these activities of the brand do not contradict each other, giving the impression of fraud. Synergy of brand communication is achieved through alignment with its personality, crowning the so-called pyramid brand. The development of brand communications theory can be characterized by two opposing trends. 
Stockholm School of Economics revolutionary breaks with all the traditions of strategic planning, both in the economy and in communications. Promoted Funky Business, and the future of humanity is represented as the Dream Society. Model '4D-branding' Thomas Gad (Gad, 2001), the author of the Swedish business bestseller of the same name, does not contain even a hint of a cognitive decision-making model. Brand simulacrum is modeled according to the four pseudo - measurements of identity, similar to the figure.

David Aaker, professor of business-school of the University of California at Berkeley, saves a cognitive measurement scale, allowing it to offer a methodology for assessing the value of the brand (Aaker, 2003). However, Aaker's model thus enters into the territory of structural and semiotic research methods, which categorically do not accept the Gestalt psychologists. This direction in the communication strategy will be discussed below. While we consider the explanatory potential of the theory of brand communications in the field of social planning.

The role of the actors of social communication can be given to charities, non-profit organizations, individuals, who take on the role of volunteers, as well as government agencies, commercial and political structures. Trust to them is based on the faith in altruistic motives for their decision to take up these or those socially important problems. However, if this belief is shaken, the reputation is very difficult to restore.

For example, an international consulting company the CAF, which annually publishes the 'goodness' ratings of the peoples, record low figures of Russian donations to charities. This unfavorable figure has a history associated with the Children's Fund activity Lenin, the first charitable foundation in Russia, created in the wake of the romantic mood adjustment. Its first chairman was the famous writer Albert Likhanov. During 1987-1990 - years of Fund's triumph, it received more than 350 million rubles of private donations (Charities Aid Foundation (CAF) - Charity Giving Made Simple, n.d.).

Until now, the Russians attitude to charities is suspicious. And not only among the population, but also in the Institute of Journalism. Some kind of a silence loop was formed, which only exacerbates the situation with the funds. Much more dynamic is a practice of targeted assistance that is being developed due to the social networking platform. Fundraising is organized by volunteers, detailing adversity to their subscribers, reporting on the results. Since the account of a social network is daily diary entries, as well as the reaction to the publication and statements of 'friends' and 'friends of friends', the subscribers have formed a volume imagination of individuality of volunteer, it is based the foundation for trusting relationships. 
Undoubtedly, officials, businesspersons, politicians are difficult to get the trust. All of them have their own business objectives, the achievement of which is not always the same as the care of social health. Through journalistic publications, the facts get in the public space and are set to a cautious attitude to such benefactors. In particular, from the perspective of Gestalt psychology, given at the beginning of this article, the scandalous situation with the KFC brand, to join the fight against breast cancer, is explained. Roles of the producer of fast food and the guardian of the nation's health are perceived in the modern world as mutually exclusive, and their combination is evaluated as an extreme degree of hypocrisy. However, Gestalt psychology cannot give an answer to the question: when and how to transform a frame of perception of socially responsible companies. Why does the allocation of funds from commercial activities in the 1970-1980 mean social responsibility, and in the 2000s - the hypocrisy?

\section{Semiology and methods of structural analysis in the design of communication strategy}

The answer to this question is given by semiology that develops on the theoretical basis of semantics - the science of the laws of the construction of the meaning of the minimum units of language. Traditionally, such problem was governed by semantics - a science that deals with building sense from the smallest parts of language. The history of semantics goes back to Medieval times; however, it begins to develop as a separate science at the turn of the 19th century because of discoveries made by F. de Saussure, Ch. Morris, Ch. Peirce, who proposed an idea of semiotic nature of language and argued about interpretation, sense and meaning as universal rules of language systems. While working on the relationship between a signifier and what it signified, F. de Saussure stated that 'there is nothing in a language except for differences' (Saussure, 1999), for consciousness is only able to perceive differences. He also provided the scientific world with a model of arranging a meaning by introducing a term called a structure of semantic field, which is constituted by the two axes of Syntagma and Paradigm. The syntagmatic axis expresses grammatical relations between the symbols, thus tying together variables of certain categories. The paradigmatic axis signifies meaning and expresses the individual practice of universal grammar implementation.

The method of structural analysis was later adopted by postmodernists. The language is a tool of social reality construction; therefore, each and every cultural phenomenon can be regarded as a symbolic system capable of revealing the secret of sense construction. 
The ideas of structuralists forced the society to reconsider the rhetoric, which traditionally regarded metaphor and metonymy merely as expressive figures of speech. R. Jacobson considered them to be not figures of speech, but rather a semantic model which manages a choice of expressive forms as a syntagma (Jakobson, 1987). Metaphor, which arranges the relations between the symbols' similarity-wise, is seen as a paradigm. In the first case, the logic of consciousness takes part in construction of senses; in the second case the logic of unconsciousness and imagination both lead the way. This idea was perceived by Soviet structuralist M. Lotman, considering meta-structure of the art text as a marker of an ideological and artistic style, worldview code (Lotman, 1992).

The following scientific findings were divided, and two disciplines took over - cognitive science and semiology. The representatives of the cognitive branch operate with the category of frame (a cognitive construction). A frame is a minimal operational unit of thought, which serves as a benchmark to find the differences and similarities of the observed phenomena. Depending on the complexity of the system parameters, which organize frames of perception, we can distinguish (cognitive-wise) complex and simple individuals. For example, in the practice of marketing communications while preparing the psychographic profile of the audience, a technique called 'repertory grid' is widely used. It was invented by American psychologist J. Kelly (Kelly, 2000), the author of the theory of personal constructs. The identity of the individual, in his opinion, is an organized system of more or less important constructs, or the frames. Cognitively speaking, a simple individual operates with binary assessments 'I like it / I do not like it'; a complex system of those assessments characterizes a sophisticated personality and compound perception of the society.

Semiologists actively work with the category of meaning. In contrast to the Gestalt psychologists, they do not give up trying to follow the logic of sense. However, this is not a formal logic, and the game - without rules, without limits of time and space. The French philosopher Gilles Deleuze speaks of two types of episodes in the development of ideas, literally calling them 'a passenger without a seat' and 'empty space' (Deleuze, 1998). Undoubtedly, this extravagant statement echoes the ideas of Jakobson and Lotman about the development of meaning with respect to Grammar axes and paradigms, using the model of metaphor or metonymy in the organization of communicative practice. Indeed, the dynamics of social and cultural processes manifested in the fact that the existing rules, forms, meaning that up to sometime have not been challenged, show a sudden irrelevance in relation to the new challenges, experiences. Meaning, forever plying somewhere 'passenger' is 'unreturned gift' and all the ensuing problems in the relationships. 
Thus, cognitive and semiological approaches do not exclude but complement each other. Their contradiction is removed by the idea of the communication being regarded as a process aimed at mutual understanding, which is deployed in time and has a hierarchical nature (Alexeev, 2002; Klyukanov, 2010).

At its first stage, communication is similar to a monologue. The actual order is regarded by 'The Speaker' as a natural one; it doesn't occur to him/her that somebody else might see it differently. Communication is comprehended here as channeling of information and its aim is to define an ontological status of a subject in the clearest way in order to respond to a question 'What is it?'

The ideas about 'The Other' picture of the world are extremely scarce, and the possibility of 'adjustment' of the Speaker to his/her companion is limited by registration of reactions to different communication stimuli. As a result, respectable statistics is accumulated, which can then allocate significant incentives that cause the desired reaction of the 'Other'. This knowledge allows one to answer a priority question for the Speaker which is, 'How to do it?' In philosophy, this level of questioning and the corresponding stage of the dialectical deployment of communicative process is called praxeology.

Phase of epistemological development of communication is characterized by arranging in order a diverse and chaotic experience emerged from practice. Redefining of the experience of 'Others' into their own codes happens at this stage; thereby a search for a common denominator in the experience of the Speaker and Others takes place which results in an opportunity to compare these experiences.

A move to the next development cycle of communication - axiological can be described as a movement from 'deliberate ignorance' to 'conscious awareness'. The Speaker is able to answer the question, 'Why is it important to Others?' Understanding of logical-semantic structure of the 'Other's' worldview is formed, as well as the principles of meaning generation by the 'Other' consciousness. At this stage psychological annex to the personal space of the 'Other' becomes possible, as well as the impact on it 'from the inside', with the help of practices, reinstallations of the anchors and other instruments of psycholinguistic reprogramming.

At the highest stage of foreign culture adoption there is a new degree of orientation freedom in a different logical-semantic space, in another discourse. Indeed, this space is no longer perceived as 'foreign' for emotional and sensual experience of living in other people's codes makes this experience a personally valuable one and opens another angle of view on the usual order of things. Communication regains ontological status when there is a feeling of trust in the other picture of the world; what was perceived as surreal, receives the status of 
an understandable (but not familiar) reality. Return to the starting point takes a whole new level: it is a reflexive attitude to the new reality. Major task of communication at this stage is resolving trust issues, and the main question asked by the Speaker is, 'What is right?' This aforementioned cycle of communication is called an ethical one.

\section{The principle of structural analysis in the diagnosis of social advertising}

In the practice of communication management, concept of communication levels is realized in the process of development of communication strategies. Depending on the results of the target audience research profile - their knowledge on the communication subject, motivations and values - a decision is made regarding positioning.

Communication is built either by relying on awareness, that is, by appealing to the existing cognitive representations of the norms of social practice, or by changing the relationship when the semantic associations extend beyond the usual social grammar and turn to remote individual practice. Attitude to the proposal changes along with the change in the context of perception. However, the audience should be ready to accept such creative maneuvers, having formed an idea of reality as a reference and an example for comparison. Otherwise, the message will be perceived as nonsensical.

For instance, in 2013 Russian Federal Service for Supervision of Communication, Information Technology and Mass Media has banned an Australian social commercial 'Dumb ways to die' (Dumb ways to die, 2017). The video is made in an ironic style and consists of series of pictures where the cartoon heroes are dying because of stupid things: set fire to their hair, poke a grizzly bear with a stick, take expired medicine and eat expired products... Any irony in relation to death is perceived as blasphemy in Russian culture, even if it occurred because of the victim's own stupidity. Therefore, the standards of verbal behavior for such situations had previously developed. Social posters and promotional films about the safety standards of living are oriented on training, and that is why a certain appropriate style of storytelling is chosen to tell about accidents. The conflict triggered by the Australian commercial was inevitable: Russian society is not ready for a sharp breakdown of these patterns. Not that it was even needed. The ability to step back in order to look at someone else's misfortune, laugh at the 'stupidity' of the victim are signs of individualism, which signifies problems with solidarity and lack of social capital.

Every culture values and protects its own system of moral and ethical standards to maintain social order. The modernist ideology stems from the idea 
of a rational nature of a person and of necessity to control passions and irrational behavior. Thus, social communication inside this paradigm of values often implements feelings of guilt and fear. But since philosophical ideas of Nietzsche and Freud condemning the repressive function of culture had become part of mass consciousness, moralistic tone of social advertising began to cause irritation.

This is particularly evident in cases where an advertiser crosses the line and creates inappropriate messages. For example, in 2010 the Russian public indignation was raised by an anti-smoking poster within the social advertising project, 'You don't care, do you?', initiated by the largest operator of outdoor advertising in Russia 'Russ Outdoor'. The poster shows a baby and a cigarette being extinguished against the baby's body. There is no doubt about the inherent message being on the danger of passive smoking, and yet the sadistic image overshadowed it. Here is one of the responses we could not agree more with, 'Sadistic "social treatment" somehow brings to mind not the physical health of children, but the mental state of adults pursuing this action. Maybe I'm wrong, but I get a sick feeling every time I pass this shield' (Beljaev, 2010).

Shocking British advertising with the image of a cockroach sticking out of a baby's mouth also tried to awaken a sense of guilt among the middle class, drawing attention to the problems of socially vulnerable citizens. Judging by discussions on the Internet, the social campaign by Barnardo was associated with the discussion of the British society of a heavy tax burden, which bears the middle class by paying taxes, which go to rather generous social benefits. The shocking image of a baby was perceived by good citizens as a motivation for the next step - to accept the injustice of wealth inequality and, consequently, pursue on donations and tax increases. However, the sense of social solidarity in the UK has undergone serious testing by the consumer ideology of individualism that was adopted by politicians. A social stratum of citizens, who were labeled by psychographic studies as 'hamsters', was formed. 'Hamsters' of the 2000s are not willing to pay, and they do not wish to think about moral evaluation of their behavior.

Thus, the two scandalous events associated with shocking images of babies, are fundamentally different. In Russia, the negative reaction was triggered by the stupidity of advertisers who failed to choose the right language of communication. In England, there was a cognitive conflict between moral requirements and a selfish desire for material well-being and comfort; an unexamined complex repressed into the unconscious, which thriving citizens preferred not to stir up.

An appeal to the feeling of fear is also a common tool in social communication. Fear is a basic emotion and represents the unconscious bodily response to a 
dangerous situation. Among experts in the field of social advertising it is widely believed that this is the only tool that is able to 'sober up' a careless audience and get them to think rationally.

However, psychological studies of emotions contradict this belief. While describing the typical feelings and behavioral reactions, stimulated by the emotion of fear, K. Izard (Izard, 1991) noted that the nervous system appears to be suppressed, and that the thinking and behavioral activity freezes along with it.

Therefore, in order to receive positive effects of such radical instruments of public influence, it is necessary to include a positive program of action in the message. E.g. not to bully by horror of a car crash, but to instruct and tell about the consequences of driving in different speed modes, with and without seat belts, or a child seat. Rather than spook the teenage audience raised in the era of sexual revolution with AIDS, suggest ways of having safe sex, etc.

Social communication should consider the shifts in value paradigms. Returning to the example of the charitable campaign 'Buckets for the cure', which was provided at the beginning of this section, we should point out that KFC tried to build a dialogue with the target audience based on the usual procedure of corporate philanthropy of the U.S. of the 1950s. Corporations used to represent the foundation of American economic prosperity. Their activities were exclusively motivated by the concern about the national welfare. By engaging in solving social problems, they used to act in a way of their business practices: giving tax deductions to the budget or donating from profit to charities. However, in 1970 the public changed their opinion on the corporations. They became to be treated like an evil empire which manipulated American consumers for a company's own purposes and by turning them into weak-willed animals. KFC clearly underestimated this new frame of reference in the field of Postmodern social values.

Post-industrial society with a social space represented as a complex mosaic of atomized individuals, is a challenge for a culture, it must solve a complicated task of integrating diverse experiences and views of the world and find a common platform for creating common semantics for a new type of social community.

According to E. Fromm and his idea of existential needs (Fromm, 2011), which expresses the essence of human nature, a secret for a healthy society is a social environment, which would develop an essence of a human being rather than suppress it. Fromm's ideas, which were rooted in the philosophy of existentialism, evolved into the perspective of humanistic psychology. A. Maslow (Maslow, 1987), C. Rogers (Rogers, 1994), V. Frankl (Frankl, 1990), E. Neumann (Neumann, 2008) focused their research on the spiritual essence of man. The distance between the theory and practice of communication is huge, 
because in reality people have to face persistent prejudice, repressed fixations, which also make up one of human essences. Regrettably, the social nature of a human being is programmed as congenital malformation and is a split psyche in which Ego, which is responsible for the social part of a person, is separated from the Self, embodying the spiritual. Alas, in this sense the modern man is not that much different from his ancient ancestor for in a situation that requires social cooperation, the unconscious activates the binary program of 'The Self / Other'.

The external moral pressure as a persuasion tool having dependably worked in societies of the Modern, loses its effectiveness in the socio-cultural environment of the Postmodern. It seems to a man of the Postmodern convincing only that to what he independently came as a result of reflexive efforts. Do not push, but to prompt, to help a person in solving painful cognitive conflicts, correlating them with the moral norms of prosocial behavior. In other words, to build a dialogic, but not a monologic communication.

\section{The structural method in the construction of dialogical communication in the social sphere}

More visually the experience of construction of dialogic communication can be traced in the practice of creating and optimizing web-sites of charity organizations. Web-developers design the structure and design of the web-site, based on the concepts of the process of decision-making by target customers.

To be reminded that for semiologists this cognitive process reflects the usual order of the charity practice and it is understood as its grammar. Based on the brief, as well as structural-semantic research of similar web-resources, experts reconstruct the sequence of cognitive reactions of clients: what will attract his attention, how much information would be sufficient for him, etc. It is not always when the original assumptions turn out to be correct. 'Not working' website signals about the errors when it is a few visited, or visitors do not make planned target actions.

Sometimes it is enough to pass the so-called SEO-optimization, tracing with the tools of web-analytics the failure statistics from viewing pages of the website, view depth, transfers to other pages, etc. All these data allow us to make a small extra emphasis to the initial hypothesis of the decision-making model by a target audience.

There are situations when a fundamental change of the web-resource redesign - is needed. This happens when an organization establishes changes in the composition of a target audience due to a variety of reasons - a new marketing policy or gaining a new experience, allowing in another way to see already existing customers. 
For several years we have been together with our graduate student O. Andrienko (Andrienko, 2012) watching the activity of the Spanish charity association 'Ledicia Cativa'. Until 2012, this organization was represented in the virtual environment with a business card site, focused on the local community. The site structure was very concise. Firstly, it is a very low-key presentation of the project. This is a help to children from Russia who live in areas suffered from the Chernobyl disaster. Secondly, there was a section about the status of a charitable organization, in which it was mentioned about the connection with the influential Spanish religious organization Opus Dei. It is unlikely that its function can be interpreted as emotional involvement and formation of empathy by potential volunteers and sponsors. Rather, it is referring to the moral norms, following which is a mandatory component of a social status. The third section, the most detailed, saved in the new version of the site, is built up without typical questions of potential participants. For example: 'How to help, if a person has no opportunity to take a child for the whole summer?', 'Is it possible to donate tangible assets or material things, being a volunteer from this association?' ('Asociacion Ledicia Cativa Como ayudo?', n.d.). Finally, the traditional section with contacts. We can assume that for the Spanish people, who save features of traditional culture in their lifestyle and are immersed in the life of the local community, the information provided on the site would be enough to take the right decision.

However, the 'Ledicia Cativa' manages an international charity project, and interaction with representatives of another culture often stumbles with the difficulties of understanding. During the years of communication with Russian children, their parents, officials, it would seem the obvious idea of cultural difference was opened to the project participants as a revelation. For example, the Spanish faced with distrust to the motives of their activity. Indicative situation in 2010, when the Spanish holidays with the orphans from the Middle Urals were failed (Kezina, 2011). A lot of money turned out to be wasted. Return tickets, medical insurance for each child, visas, packages of documents and certified translations were paid by ordinary Spanish people. Even with the partial refund of tickets, Spanish families have lost about 400 euros for each child. The formal reason was purely bureaucratic delays - the protracted process of transferring authorities for signing the agreement about the departure of Russian children abroad by the regional ministries of education to local bodies of trusteeship. In the absence of strict regulations, a subjective factor appeared - a personal attitude of officials to the international charity. Ombudsman for Children of the Sverdlovsk Region, commenting the situation as 'very controversial and mixed', referred to the 'scandal with the American family, that tortured the adopted in Russia boy'. 
Russian parents also shared their fears with the volunteers of the project. For example, their children would be stolen. These concerns stem from the fact that the material side of life of Russian families is much lower in comparison with the Spanish. Having felt the prosperity in a Spanish family, children do not want to return home anymore. The negative outcry was intensified by rumors spread by parents whose children received negative experience in the project. Cultural adaptation on the early cycles is accompanied by a depression of child, but for this situation, adoptive Spanish families were totally unprepared.

All these troubles did not fit into the usual understanding of the Spanish about charitable activity. The grammar of role prescriptions and relationships between project participants should be reviewed. For this purpose, we use the method of structural analysis.

The meaning of a conflict and emotional experiences of the project participants becomes clear, if to consider them in the context of ritual of giving, pattern of the collective unconscious one, first described by French ethnographer Marcel Mauss (Mauss, 1996). Poisoned gift, the central symbol of this ritual, characterizes the essence of the relationships which the donor and the bestow enters. These are relationships of power, together with a gift a person acquires dependence on the donor. Meta-structure of the ritual is a complex system of settings, which regulate relations of the members of the community (Starykh, 2002). For example, the gift cannot be refused from, because this action leads to a 'loss of face', a rupture of social ties. Despite the fact that different types of societies are characterized by varying degrees of independence of the individuals from society, the destruction of social ties is always dangerous for the health of the community. In order to maintain its own social status, it is necessary to make a back gift - 'return gift'. Moreover, such structural elements of ritual, like a circle of bestows, gift's generosity, the method of handling-in, the timing of the return of debts, etc. are able to regulate the relationships between the donor and the bestow in the very wide range - from aggression and psychological subjection to the hearty friendly relations and equivalent positions of the participants of symbolic exchange.

Speaking in a similar vein about the case of 'Ledicia Cativa' we have concluded that the philanthropists, taking as a reference point a mental map of their own, traditional Spanish world, have fallen into a trap of a more complex scenario in which, in addition to 'Their own', also 'Strangers' appear. It follows that a more complex regulation of relationships between participants is required. It is necessary to launch a scenario such as 'Their own people together solve worrying everybody problem'. This grand strategy eliminates the risk of confrontation 'their own' and 'strangers', protects against suspicion of psychological aggression and attempt of subjection. 
How to do it? With the instrumental issues, as we have already found, it is better to apply to cognitive methods. However, if we want to get a coherent model of the investigated situation, it is necessary to relate the concepts of prosocial behavior and the ritual of giving.

The semantic intention embedded in the archetype of donation allowed us to capture the internal structure of the conflict and to imagine the dialectic of relationships of the donor and the bestow on the scale with opposite poles: enmity and friendship. The model of prosocial behavior is a logical sequence of decision-making process about the assistance; its configuration depends on the type of the motives of helping behavior, and situational factors, such as the influence of the group. The development of the scenario 'Their own' is possible in a particular socio-psychological environment based on empathic understanding among project participants. Correlating a real and desired situation with a map of the mental process, the weak units are being discovered in the original communication strategy. To convert to 'Their own' people with different social and cultural experiences, special attention should be paid to the cognitive processes that were not originally considered. First, it is emotional involvement. Secondly, the impact on the reflective stage of the decision making: social psychologists proved that a detailed clarification of the circumstances of adversity affects the increasing of empathy. Apparently, all the same was understood by the leaders of the charity project 'Ledicia Cativa' because this policy can be traced in the redesign of the site.

The visual appearance of the logo has been changed. Previously, it was the ship and shell - Galician symbols, now it is the image of children on the green lawn. Undoubtedly, such a change symbolizes a valuable shift in the corporate culture of the organization - from ethnocentrism to universal existential values.

Secondly, a volume section about the activity 'Ledicia Cativa' has appeared. Indeed, a charitable organization, acting as a mediator between the Spanish and Russian communities, should inspire confidence of both sides. In particular, much attention is paid to the internal regulations governing the conduct of volunteers and sponsors. It emphasizes technology of assistance: temporary stay of children in the Spanish families during summer months or winter holidays. Basically, these are children who have a family. For the orphans from children's homes, this program also spread, however, by the internal charter of the 'Ledicia Cativa' the adoption of Russian children is not allowed. Thus, the organizers of the project are rebuilt from international criminals who under the guise of charity entered a slave trade of children from the third world countries. Such scandals increasingly fall on the pages of foreign media. The community of some countries, such as Romania, Guatemala, Indonesia, Kenya, insists on the 
introduction of the law into effect about the prohibition of children adoption by foreign citizens (International adoption should be banned - DebateWise, n.d.; In wake of Engeline's death, KPAI proposes ban on foreign adoption, n.d.).

Thirdly, a volume section with a description of the Chernobyl disaster, the consequences of radiation exposure to children's health, with the medical advice of health improvement after a holiday in Galicia has appeared. This section focuses on the Spanish volunteers and sponsors so that they are able to make a balanced decision and to have an opportunity to correlate the scale of the problem and the proposed ways of help.

Based on our understanding of the problems that have arisen in the course of an international charity project 'Ledicia Cativa' it would be possible to recommend additional tactics of communication management.

For example, a large reserve of emotional impact lies in the historical memory that unites both folks. One section could effectively work on the objectives of the project. This section is related to the history of the Spanish revolution of 1937, when by the request of the Republicans the Soviet Union took under its guardianship the Spanish children. Seeing off the children to the Soviet Union, the Spanish parents told their children that they were going to a country where the life is a paradise and an example to follow. Indeed, the small Spanish were given the best of everything - Pioneer camps, doctors and the enhanced medical care, delicious food (Russkie Ispancy, 2017). It should be noted that the Spanish family remember about these events, they talked about it in an interview with the project supervisors. For many people the aid to the Russian is the return of the debt. It would be nice to update the story in the memory of Russian parents, it could remove a complex of 'unreturned gift' and all the ensuing problems in the relationships.

Also, we would like to pay attention to another conflict-factor in charitable projects. This diffusion of responsibility when someone avoids personal participation in activities, thinking that it's all already thought out and made by someone else. This effect is also present in communicative behavior. For example, Russian parents resent the Spanish because they get little information about their children; and Spanish families believe that the supervisors are responsible for liaison with Russian parents. On the other hand, the Spanish families are offended that by the return of children to Russia, they do not get letters from Russian parents. They are concerned about the attention to the feelings of people who had time to become attached to the baby. If Russian parents were focused on human relationships rather than bureaucratic regulations, they would be terrified of themselves. In connection with the foregoing, it is clear that the necessary technologies provide multiple horizontal relations among 
project participants. Perhaps in the near future, the predominant format for web-resources of charity organizations will be the social networks, which are supposed to be the best way to ensure horizontal communication of participants.

\section{Conclusion}

Two approaches to designing communications - positivistic and postmodern (based on a platform of humanitarian disciplines) - are perceived as oppositional. At one time, one of the founders of the Department of Advertising and Public Relations of the Faculty of Journalism of Moscow State University, Professor V. Uchenova (Uchenova, 1999; Uchenova, 2004) formulated this contradiction as a war of marketing and cultural concepts of advertising. Alas, this contradiction has not yet emerged from the acute stage.

Key international scientific journals, oriented toward the American school of communication design, regard as methodologically weak any manuscript, that does not fit into the format research 'factors, that stimulate the behavior of the target audience'. In particular, the author heard such accusations repeatedly.

The consequences of this war also affected the advertising education in Russian universities, as the domestic education is also oriented towards the American model.

From the standpoint of dialectical logic, any of the extremes taken for truth, keeps the system (and advertising theory, and advertising education) in an unstable state, which has a lot of negative consequences. It is necessary to integrate the existing experience of reflection and bring the theory of marketing communications to a new level. The undoubted value of positivistic models is in the project approach in solving communicative problems. Communicative strategy, understood by positivists as positioning, allows to map the mental processes of the target audience and focus on the problematic links. However, the arsenal of the positivist sciences and the position of the 'external observer' do not allow to the researcher to understand the meanings of various reactions of the 'object of observation'. Interpretation of this hidden meaning, which governs the behavior of the Other, constitutes the exclusive competence of the humanities.

\section{References}

AAKER, D. (2003). Building strong brands. Moscow, Publishing House of Grebennikov.

ALEXEEV, N. (2002). Proektirovanie i refleksivnoe myshlenie [Design and reflexive thinking]. Development of Personality, 2, pp. 85-103. Available from: http://www.rl-online.ru/info/266.html [Accessed 5th February 2017]. 
ALEXEEVA, O. (2008). Istorija doverija $v$ nedoveritel'nye vremena: Istorija rossijskoj blagotvoritel'nosti [History of confidence in untrusted times: Modern Russian charity]. Moscow, Eksmo, pp. 12-16.

ANDRIENKO, O. (2012). Kody vosprijatija $\mathrm{v}$ postroenii kommunikativnoj strategii blagotvoritel'noj organizacii [Codes of perception in the construction of communication strategy charity]. Public Relations and Advertising Communications System. Collection of Scientific Works of the Department of Advertising and Public Relations, 8, pp. 181-186.

Asociacion Ledicia Cativa ¿Como ayudo?. Asociacionlediciacativa.org. Available from: http://asociacionlediciacativa.org/como-ayudo/ [Accessed $5^{\text {th }}$ February 2017].

BELJAEV, A. (2010). Zacepilo! V Ekaterinburge tushat okurki v tele mladencev [Got Hooked! In Ekaterinburg cigarette butts are extinguished in the babies' bodies]. Komsomolskaya Pravda. Available from: http://www.ural.kp.ru/ daily/24458/620733/ [Accessed 5th February 2017].

Charities Aid Foundation (CAF) - Charity Giving Made Simple. Cafonline.org. Available from: https://www.cafonline.org [Accessed 4th February 2017].

DELEUZE, G. (1998). The logic of sense. Yekaterinburg, Business Book. pp. 59-67.

DERRIDA, J. (2000). Freud and the scene of writing. In: J. Derrida, Writing and difference, $1^{\text {st }}$ ed. St. Petersburg, Academic Project, pp. 252-292.

Dumb ways to die. (2017). YouTube. Available from: https://www.youtube. com/watch? $\mathrm{v}=$ DNjfw_waYyQ [Accessed $5^{\text {th }}$ February 2017].

FRANKL, V. (1990). A man in a search of sense. Moscow, Progress.

FREUD, S. (2004). About dreams. Moscow, AST.

FROMM, E. (2011). The sane society. Moscow, AST, Astrel.

GAD, T. (2001). 4D branding: Cracking the corporate code of the network economy. St. Petersburg, Stockholm School of Economics in St. Petersburg.

Greed, cancer and pink KFC buckets. The Huffington Post. Available from: http:// www.huffingtonpost.com/john-robbins/breast-cancer-awareness-g_b_577574. html [Accessed $4^{\text {th }}$ February 2017].

ILYIN, E. (2013). Psihologija pomoshhi. Al'truizm, jegoizm, jempatija [The psychology of help. Altruism, selfishness, empathy]. St. Petersburg, Piter, pp. 20-25.

In wake of Engeline's death, KPAI proposes ban on foreign adoption. Jakarta Globe. Available from: http://jakartaglobe.beritasatu.com/news/wake-engelinesdeath-kpai-proposes-ban-foreign-adoption [Accessed $5^{\text {th }}$ February 2017].

International adoption should be banned. DebateWise. Available from: http:// debatewise.org/debates/1005-international-adoption-should-be-banned/ [Accessed $5^{\text {th }}$ February 2017].

IZARD, K. (1991). Psychology of emotions. St. Petersburg, Piter, pp. 292-319. 
JAKOBSON, R. (1987). Work on poetics. Moscow, Progress, pp. 89-99.

KELLY, G. (2000). A theory of personality. The psychology of personal constructs. St. Petersburg, Rech, pp. 137-235.

KEZINA, D. (2011). Ural'skih detdomovcev ne pustili na kanikuly v Madrid. [Ural orphans were not allowed for a vacation in Madrid]. Rossiyskaya Gazeta. Available from: http://www.rg.ru/2011/01/27/reg-ural/detdom.html [Accessed $5^{\text {th }}$ February 2017].

KLYUKANOV, I. (2010). Kommunikativnyj universum [Communicative universum]. Moscow, Russian political encyclopedia (ROSSPEN), pp. 83-103.

LOTMAN, M. (1992). Rhetoric. In: M. Lotman, Articles on Semiotics and Topology of Russian Culture, $1^{\text {st }}$ ed. Tallinn, Alexander, pp. 167-184. Available from: http:// yanko.lib.ru/books/cultur/lotman-selection.htm [Accessed $5^{\text {th }}$ February 2017].

MAUSS, M. (1996). Essay on the gift. The shape and the base of exchange in archaic societies. In: M. Mauss, Society. Exchange. Personality, $1^{\text {st }}$ ed. Moscow, Eastern Literature RAN, pp. 85-111. Available from: http://www.e-reading.club/ book.php?book $=145170$ [Accessed $5^{\text {th }}$ February 2017].

NEUMANN, E. (2008). Depth psychology and a new ethic. Saint-Petersburg, Azbuka-klassika.

ROGERS, K. (1994). View to psychotherapy. Human formation. Moscow, Progress, Univers.

ROSS, B. \& RICHARDS, J. (2008). American academy of advertising - a century of advertising education. Aaasite.org. Available from: http://www.aaasite.org/page1557250 [Accessed $4^{\text {th }}$ February 2017].

Russkie Ispancy [The Russian Spanish]. (2017). YouTube. Available from: https://www.youtube.com/watch?v=CyIAJrxOl8g [Accessed $5^{\text {th }}$ February 2017].

SCHULTZ, D., TANNENBAUM, S., \& LAUTERBORN, R. (1994). The new marketing paradigm. Lincolnwood, Ill., NTC Business Books.

Social'naja reklama shokirovala britancev [Social advertising shocks Britons]. (2017). RBC. Available from: http://top.rbc.ru/wildworld/03/12/2003/54899. shtml [Accessed $4^{\text {th }}$ February 2017].

SAUSSURE, F. (1999). Course in general linguistics. Yekaterinburg, Ural university, pp. 123-136.

STARYKH, N. (2002). Kul'tura darenija: ot arhaicheskih ritualov do sovremennyh promoushn-akcij [The culture of donation from archaic rituals to modern promotion actions]. Moscow University Journalism Bulletin, 3, pp. 54-66.

STARYKH, N. (2016). Theory of communication management: Origin, formation and development prospects in the paradigmatic space of positivism and postmodernism. Communicology, 4(3), pp. 30-61. Available from: http://www. communicology.us [Accessed $4^{\text {th }}$ February 2017]. 
The dangers of cause marketing. Bloomberg.com. Available from: http:// www.bloomberg.com/bw/articles/2014-09-03/the-dangers-of-cause-marketing [Accessed $4^{\text {th }}$ February 2017].

UCHENOVA, V. (1999). 'Razvilka' v reklamovedenii: Teoriya i real'nost' ['Fork' in advertising: Theory and reality]. Moscow University Journalism Bulletin, 4, pp. $18-21$.

UCHENOVA, V. (2004). Ne marketingom edinym... [Not a single marketing...]. Collection of Scientific Works of the Department of Economic Journalism and Advertising, Moscow, MSU Faculty of Journalism, pp. 5-17. 